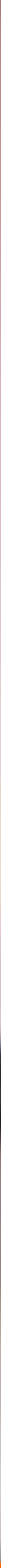

\title{
A revolução grisalha: mulheres (re) semantizando signos do envelhecimento
}

The gray revolution: women (re)semantizing signs of ageing 


\section{[DENISE CASTILHOS DE ARAUJO]}

Doutora em Comunicação Social. Estágio de Pós-Doutoramento no PPGCOM Processos Midiáticos da Unisinos

E-mail: denisecastilhos@gmail.com

[resumo] Este artigo objetiva discutir os significados possiveis da velhice a partir da midiatização de um movimento social que ocorre no Brasil: a aceitação e uso de cabelos brancos por mulheres, principalmente na divulgação de conteúdos no espaço virtual. Parte-se do pressuposto da existência de uma significação recorrente na sociedade brasileira: 0 envelhecimento visto nos cabelos brancos. Discute-se os novos sentidos evidenciados nas publicações selecionadas, problematizando o tema da seguinte maneira: como mulheres midiatizam novos padrões culturais/ estéticos em relação à sua aparência?

[palavras-chave]

corpo; moda; velhice; midiatização; cabelos brancos e grisalhos.

[abstract] This article aims to discuss the possible meanings of old age, based on the mediatization of a social movement: the acceptance and use of white hair by women in Brazil, especially in the dissemination of this content in the virtual space. The starting point is the assumption of the existence of a recurring connection in Brazilian society between ageing and white hairs. The article discusses the new meanings evidenced in the selected publications, problematizing the theme in the following way: how women mediate new cultural/aesthetic patterns regarding their appearance?

[keywords] body; fashion; old age; midiatization; white and gray hair. 


\section{Introdução}

Este artigo é parte de uma pesquisa em desenvolvimento em estágio de pós-doutoramento no Programa de Pós-Graduação em Processos Comunicacionais, na Universidade Unisinos, que tem por objetivo verificar como o envelhecimento é midiatizado em espaços virtuais. Este estudo trata especificamente de discutir a respeito de um dos signos do envelhecimento e que, nos últimos anos, tem sido tema de debate recorrente: os cabelos.

0 corpo é um dos primeiros textos usados pelos indivíduos para se comunicar, e essa construção discursiva interessa à moda, uma vez que se trata de um tipo de linguagem usada pelos indivíduos. Neste estudo, há a preocupação em identificar novos sentidos dados a um dos signos mais recorrentes quando se pensa em velhice: os cabelos brancos. Apresenta-se tal interesse uma vez que a presença de indivíduos com mais de 60 anos, em diversos espaços sociais brasileiros, tem-se revelado uma questão que merece cada vez mais ser discutida, pois, de acordo com os dados da Secretaria do Desenvolvimento Humano, do governo brasileiro, até 2050 o número de pessoas velhas (com mais de 60 anos), no país, será em torno de 30\% (BRASIL, 2013).

Assim, constata-se que esse público participa/participará cada vez mais intensamente da sociedade, merecendo que se reflita acerca de suas relações, percepções e interações na sociedade. Essas interações se dão em diversos campos sociais, tais como trabalho, educação, comunicação, moda, no virtual, entre outros.

Considerando esses espaços, este artigo propõe a identificação de sentidos possiveis, em publicações de grupos de redes sociais e sites que tratem da temática proposta neste estudo: cabelos brancos/grisalhos.

\section{Corpo, moda e midiatização}

0 corpo humano tem sido regulado há séculos pelos padrões culturais das sociedades. Tais regulações serviram/servem para normatizar os formatos dos corpos, indicando aqueles que podem ser considerados como mais aptos a participar de maneira efetiva nos grupos sociais. Ou seja, o corpo passa a ser tratado, em alguns momentos, como um passaporte para o indivíduo circular livremente nos espaços sociais desejados. Muitas vezes, tais regras também podem ser indicativas da beleza, aspecto caro para muitas sociedades, tais como a brasileira, pois relacionada ao sucesso, ao prestígio. 
Goldenberg (2006, p. 118) afirma:

No Brasil, e mais particularmente no Rio de Janeiro, o corpo trabalhado, cuidado, sem marcas indesejáveis (rugas, estrias, celulites, manchas) e sem excessos (gordura, flacidez) é o único que, mesmo sem roupas, está decentemente vestido (GOLDENBERG e RAMOS, 2002). Pode-se pensar, neste sentido, que, além do corpo ser muito mais importante do que a roupa, ele é a verdadeira roupa: é o corpo que deve ser exibido, moldado, manipulado, trabalhado, costurado, enfeitado, escolhido, construído, produzido, imitado. É o corpo que entra e sai da moda. A roupa, neste caso, é apenas um acessório para a valorização e exposição deste corpo da moda.

Então, se o indivíduo ostenta um corpo que segue os padrões indicados/desejados, provavelmente será bem aceito na maioria dos grupos sociais dos quais faça parte. Se, por acaso, seu corpo não corresponde ao desejado ou orientado pelo grupo, ele deverá ser adequado a tais normas, por meio de atividades físicas, intervenções cirúrgicas, uso de medicamentos, até que ele se enquadre no perfil estipulado (GARCIA, 2005).

0 corpo é considerado um "primeiro veículo de comunicação" (GARDIN, 2008, p. 75), que pode ser usado de maneira a produzir mensagens a partir de várias linguagens acessadas (roupas, acessórios, maquiagem, cabelos). Dessa forma, pode-se pensar que a moda é uma linguagem, pois composta de signos indiciais e simbólicos, constituindo mensagens elaboradas a partir do arranjo de tais signos (GARDIN, 2008).

Sob esta perspectiva, cogita-se o corpo como texto, o qual transforma-se em objeto midiático, trazendo consigo "elementos de reflexão e de leitura, articulando a discursividade pontual[...]" (GARCIA, 2005, p. 31).

Evidentemente, na materialidade desses textos será possivel perceber a influência da cultura, desvelando informações a respeito dessa composição textual. Ou seja, o corpo é uma "caixa complexa de informações, que contém diferentes saberes a respeito do homem e do mundo (HOFF, 2002 apud GARCIA, 2005, p. 31-32).

Villaça (2007) sugere que se pense os textos culturais elaborados como estruturas que devem ter seus sentidos e interpretações relacionados a um terreno político das relações de sentido. Assim, "a moda dada como um processo cultural produtor de sentidos, constrói posições de sujeito, identidades individuais e grupais, cria códigos que guerreiam entre si, num fórum que se globaliza progressivamente" (VILLAÇA, 2007, p.144). 
Ainda segundo a autora, a moda pode sugerir estratégias ao corpo para que se expresse, a partir de recursos estéticos e de consumo, podendo funcionar como "elementos de cidadania, democratização e comunicação, [...] exclusão elitista, via códigos simultaneamente rígidos e sutis [...]" (VILLAÇA, 2007, p.145).

Neste estudo, reflete-se sobre os novos sentidos apresentados em discursos a respeito de uma espécie de movimento que, desde 2013, vem sendo compartilhado, pela internet, em sites e redes sociais, qual seja, a aceitação e uso de cabelos grisalhos ou brancos pelas mulheres. Os cabelos embranquecidos ou grisalhos são índices de envelhecimento muito perceptíveis visualmente, podendo significar que a juventude, a beleza e o vigor estão sendo substituídos por outras caracteristicas físicas comuns ao processo de envelhecimento, mas, muitas vezes, não muito bem aceitas socialmente (rugas, manchas, ressecamento da pele, dificuldades motoras, entre outras).

Apesar da dificuldade de aceitação dos sintomas e do processo de envelhecimento, o que se tem visto é cada vez mais o aumento do número de pessoas com mais de 60 anos: a sociedade está envelhecendo.

\section{Velhice no Brasil}

A população brasileira envelhece em ritmo intenso. Isso, entretanto, não é uma exclusividade deste país, pois indivíduos no mundo todo têm mostrado altos índices de longevidade. Os resultados de pesquisas demográficas apontam para a possibilidade de existência de um número muito elevado de indivíduos com mais de 60 anos brevemente. $\mathrm{Ou}$ seja, segundo o Instituto Brasileiro de Geografia e Estatística (IBGE), em documento publicado em 2002 (IBGE, 2002), há a projeção de que em 2050 a população de pessoas idosas poderá ser de quase dois bilhões no mundo todo, o que equivalerá à mesma quantidade da população de 0 a 14 anos de idade, dados que são confirmados por outro documento, elaborado pela Organização Mundial de Saúde (OMS), reforçando que 80\% desses indivíduos residirão em países em desenvolvimento (WORLD HEALTH ORGANIZATION, 2005).

Diante dessa situação, é inevitável que estudos a respeito desse grupo social sejam realizados, principalmente em virtude das alterações de caracteristicas que os idosos atuais têm demonstrado, em comparação com os idosos do século passado.

Dessa forma, verifica-se que diversas áreas de estudo, como a Gerontologia, a Sociologia, a Medicina, a Comunicação, a Antropologia e a Moda 
demonstram preocupação em discutir questões, pertinentes a cada ciência, relacionadas ao envelhecimento populacional.

Um dos primeiros e mais conhecidos estudos, sob a forma de reflexão de sua própria situação, foi realizado por Simone de Beauvoir na década de 1970, quando ela mesma se deparou com essa fase da vida.

A autora menciona que o avanço da idade passou a ser visto como um período de perdas e dependências, e, além disso,

[...] as pessoas idosas são encaradas como membros inferiores. Muitos consideram insulto qualquer alusão a sua idade: querem julgar-se jovens, custe o que custar: preferem acreditar que estão doentes, mas não velhos. A outros, parece mais cômodo serem tidos por velhos, mesmo prematuramente: a velhice proporciona álibis, autoriza o rebaixamento das exigências; entregar-se a ela é menos cansativo que recusá-la (BEAUVOIR, 1970, p. 10).

Na citação de Beauvoir, pode-se cogitar a percepção da velhice sob dois aspectos: como algo incômodo, não desejado, ou como a possibilidade de o individuo ser tratado com mais tolerância na sociedade. De uma ou de outra maneira, o idoso é identificado socialmente e sua atuação é mais intensa nas últimas décadas, por conta de políticas públicas voltadas para esse grupo social.

No Brasil, muitos estudos foram desenvolvidos a partir da década de 1990 a respeito do envelhecimento, pois foi um período em que se viu a promulgação de leis para a proteção da pessoa idosa, tanto no país quanto no exterior. Leis que designavam a necessidade de igualdade do velho aos demais indivíduos, assim como assistência para a saúde e financeira, esta sob a forma de aposentadoria ou pensão. Se, na década de 1970, 0 idoso estava fadado a passar dificuldades, miséria, na década de 1990 verifica-se a criação de casas para o cuidado dessa população, os clubes dos idosos, com encontros semanais e a oferta de cursos em instituições destinadas exclusivamente à população com mais de 60 anos (Universidades Abertas para a Terceira Idade).

Então, se a gerência da velhice foi considerada, por muito tempo, responsabilidade da esfera familiar e privada, por questões individuais ou filantrópicas transformou-se em gestão da esfera pública. Em consequência disso, Debert (2012, p. 147) explica que 
Tentativas de homogeneização das representações da velhice são acionadas e uma nova categoria cultural é produzida: os idosos, como um conjunto autônomo e coerente que impõe outro recorte à geografia social, autorizando a colocação em prática de modos específicos de gestão.

Assim, para Debert (2012) o idoso deixou de ser um ator ausente das práticas sociais, bem como do conjunto de produções sociais, sendo possível verificar a presença deles em inúmeros espaços da sociedade.

Desse modo, pode-se inferir que a velhice, nos últimos tempos, deixou, para um grande grupo de individuos, de ser uma fase da vida que os condenava à reclusão ou ao abandono social, para se tornar um momento em que os indivíduos estão ativos nos grupos sociais. Um dos motivos que justifica essa alteração da percepção da figura do indivíduo velho advém do fato de que, com os recursos financeiros que possuem, os idosos compõem um grande grupo com poder financeiro para o consumo e que tem, efetivamente, consumido todo tipo de objetos, para si e para a família. Outros idosos, apesar da idade, preferem continuar trabalhando a fim de se manterem ativos e produtivos. Alguns dados demográficos indicam, inclusive, que há uma parcela de idosos que sustenta seus descendentes - filhos e netos -, tornando-se os mantenedores das famílias.

Diante dessas alterações, da saída da reclusão para a participação ativa na sociedade, autores como Debert (2010) sugerem que a velhice estaria assumindo características de uma "nova juventude", ou seja, o velho atual é mais ativo, mais participativo, convive mais com outros de sua idade, mantém-se no mercado de trabalho por mais tempo, viaja mais, realiza seus desejos sem culpa.

Assim, ao ser ressignificada a velhice, vê-se que certas cobranças também são bastante presentes, principalmente para as idosas, e muito em relação aos seus corpos ou comportamentos. Ou seja, presencia-se exigências de camuflagem dos traços físicos do envelhecimento, que não é exclusividade das mulheres velhas; mas elas têm, de acordo com padrões culturais, a necessidade de parecerem jovens fisicamente. Ou seja, as marcas da velhice devem ser disfarçadas, pois, apesar de a sociedade estar envelhecendo, no Brasil é o aspecto, o comportamento, o visual, o espírito, o corpo jovem que é desejado e almejado por inúmeros indivíduos.

Por outro lado, também é possivel verificar a negação de certa regra estética em relação a um signo imediatamente ligado ao envelhecimento e a irrupção de outra: o uso de cabelos grisalhos ou brancos. Observa-se que nos últimos quatro anos, muitas mulheres têm deixado seus cabelos 
embranquecerem, sem se preocupar em pintá-los; esta ação, de alcance mundial, tem sido nomeada como "revolução grisalha".

\section{Cabelos brancos/grisalhos: a midiatização e a ressignificação da} revolução grisalha

A relação moda e corpo é discutida por muitos autores que explicam como o corpo transforma-se em discursividade, representando aspectos culturais em vários momentos históricos. Villaça (2007) apresenta, por exemplo, características dos corpos de várias décadas, apontando como esses corpos deveriam ser a fim de se enquadrarem nos padrões desejados na moda de cada época. A autora salienta a parceria estabelecida entre cultura e mídia para a reafirmação dos formatos dos corpos, ou seja, a publicização dos corpos em veículos de comunicação corrobora para que este ou aquele aspecto seja valorizado em determinados momentos históricos. Para Villaça (2007, p. 226) ,"é no espaço midiático que se constroem e desconstroem aparências dotadas de atitudes próprias".

A midiatização pode ser considerada um processo recente e em evolução, que tem transformado as relações entre produção e recepção dos produtos. De acordo com Gomes (2017, p. 66), uma das principais características desse processo é "o deslocamento das pessoas do palco (onde são sujeitos e atores) à plateia (onde sua atitude é passiva)". Assim, emissor e receptor trocam de papéis a cada momento de comunicação, as mensagens não são mais de uma única direção para outra, há a circulação dessas mensagens, transformando receptor em emissor e emissor em receptor.

Ainda de acordo com o autor, dada a complexidade desse processo, observar-se nele mecanismos de produção de sentido social, tendo a linguagem papel mediador fundamental no processo. Gomes (2017) indica que a midiatização é a chave hermenêutica para compreender e interpretar a realidade, e que a sociedade percebe e se percebe a partir dos processos da mídia. Desse modo, o autor sugere que se reflita a respeito do papel dos meios massivos como espaços mediadores para a construção de sentidos.

Como já mencionado, neste estudo pretende-se refletir a respeito dos significados atuais dos cabelos brancos ou grisalhos, que podem ter significações diversas da tradicional, nas quais são entendidos como a aproximação evidente da velhice. Ou seja, o aparecimento deles remete ao processo de envelhecimento e a todas as consequências físicas e sociais decorrentes desse período. Optou-se por fazer essa verificação em textos midiáticos, que circulam nos espaços virtuais dos sites de rede social, uma vez que, no Brasil, o corpo é capital, ele é caro ao indivíduo, e a beleza e sua manutenção é requisito importante para a maior parte das pessoas. A opção pelo espaço virtual dá-se pelo fato de que o Brasil tem um número muito 
elevado de idosos que acessam a internet e as redes sociais (DINO, 2017), justificando a escolha dessa ambiência.

Ao observar publicações nos espaços virtuais mencionados, pode-se encontrar, desde 2013, uma série de textos publicados explorando o assunto: a aceitação e o uso dos cabelos grisalhos ou brancos, correspondendo ao mesmo período de publicações nos Estados Unidos e na Europa, em matérias de blogs e sites (LISA, 2017).

No Brasil, uma das primeiras matérias publicadas foi no portal iG: "Cheios de estilo, os cabelos brancos não precisam ser sinônimo de velhice e descuido. Aprenda a tratar dos fiozinhos e garantir o melhor visual sem apelar para a tintura"1. Nessa matéria, ainda se observa a ideia de que cabelos não tingidos representam não somente a velhice, mas também o descuido. Também é lembrado que o cabelo branco não é exclusividade de mulheres mais velhas, pois apresenta o relato de mulheres com 30, 40 anos que desde jovens viram seus cabelos perderem a cor natural.

No site 50 emais, organizado e mantido por Maya Santana, pode-se encontrar várias publicações relacionadas ao tema, discutindo a presença e aceitação dos cabelos brancos.

Na primeira delas, em agosto de 2013, Maya publicou uma matéria intitulada "Elas assumem cada vez mais jovens os fios brancos"2, apresentando uma série de mulheres que passaram a não pintar mais seus cabelos. A autora menciona: "A onda prateada é protagonizada por mulheres de personalidade forte, bem-humoradas e que têm um discurso pautado pela pacífica aceitação da passagem do tempo".

Assim, observa-se que as mulheres que deixam seus cabelos brancos têm algumas características - o bom humor, a personalidade forte - e não estão muito preocupadas em seguir determinadas regras, aceitando que 0 processo de envelhecimento é inevitável.

Ainda em 2013 foram publicadas mais duas matérias ${ }^{3}$ discutindo 0 assunto, com exemplos de mulheres que assumiram os brancos, ressaltando que, muitas vezes, eram interpeladas por outras mulheres ou homens, que sugeriam que pintassem os cabelos, pois o cabelo branco remetia ao desleixo. Essa é uma das significações ainda recorrentes em relação aos cabelos brancos - a falta de cuidado consigo -, como se o branquear dos cabelos fosse exclusivamente por falta de asseio, de cuidados por parte da pessoa, e não uma consequência hereditária ou da velhice.

Em setembro de 2014, o site publicou um texto intitulado "Mulheres que deixam o tempo agir naturalmente" ${ }^{4}$, falando dos cabelos brancos assumidos por algumas mulheres, mas também discutindo a manutenção do 
corpo natural, ou seja, sem intervenções cirúrgicas. Esta matéria apresenta clara crítica aos padrões estéticos que são determinados para as mulheres, independentemente da idade que tenham.

Em 2015 observa-se a publicação de três matérias ${ }^{5}$ discutindo a aceitação dos cabelos brancos pelas mulheres. Em uma delas há a menção à necessidade de uma revolução dos cabelos brancos 6 . Nessas publicações há o relato de mulheres que assumiram seus brancos com naturalidade, para evitarem a "escravidão das tinturas", como afirma Laureni, uma comerciante que aceitou os brancos com 51 anos de idade7. Em outra matéria deste mesmo ano, outra mulher disse que passou a manter seus cabelos brancos, mas que os sobrinhos "acham um horror", evidenciando que há a imposição por parte dos grupos sociais de que as mulheres evitem os cabelos brancos, ou disfarcem-nos de alguma maneira.

No ano de 2016, o site publicou nove matérias sobre o assunto cabelos brancos e sua aceitação. Em três dessas matérias é discutido o uso dos brancos/platinados por jovens, afirmando que eles estão na moda, apresentando dicas dos cuidados na manutenção desses cabelos. A autora menciona ${ }^{8}$ que isso pode ser bom, pois valoriza os brancos, colocando-os em discussão, bem como naturalizando-os. Então, se uma jovem usa cabelos brancos, pode-se pensar em uma nova significação para essa cor de cabelos; pensa-se em ruptura de regras, rebeldia, necessidade de se diferenciar dos demais.

Em 2017, são apresentadas quatro matérias cujos títulos têm expressões que chamam o leitor para refletir com a autora. Em 19 de julho de 2017, o título "Boas histórias de libertação e de aceitação dos cabelos brancos" $^{\prime \prime}$ indica que assumir o cabelo branco pode ser considerado como libertador para as mulheres. Nesse sentido, é possivel inferir que a necessidade de ir ao salão, ou de pintar os cabelos, observando uma periodicidade determinada, torna-se para a maioria das mulheres sinônimo de aprisionamento, uma rotina que controla sua aparência. $E$, no momento em que assumem os brancos e grisalhos, a liberdade chega, pois muitos cuidados serão deixados de lado - por exemplo, pintura, luzes, reflexos.

Outra matéria, publicada em 17 de agosto de $2017^{10}$, apresenta o título "Revolução na cabeça das mulheres: a moda dos cabelos brancos" e fala da experiência de uma mulher, ex-editora de uma revista de moda, que resolveu assumir os cabelos brancos, e de como esse fato causou surpresa no seu entorno. Essa matéria ilustra como determinados campos têm suas regras muito bem determinadas, pois quando um indivíduo discorda do determinado causa espanto entre os demais participantes. 
Outros dois textos foram publicados, um com o título "Com tantas adeptas, onda dos cabelos brancos chegou para ficar"11 (23 de outubro de 2017) e "Assumir a cabeleira branca significa aceitação e libertação (28 de novembro de 2017)"12. A matéria do dia 23 de outubro usa a palavra "onda", podendo levar o leitor a pensar que essa também é uma moda, como o é pintar os cabelos, mas que tal onda chegou com força e que deve ficar, ou seja, deverá ser assumida por um grande número de mulheres, fato que se tem observado. 0 outro texto reitera a ideia de liberdade, mas em que sentidos pode-se falar? Somente o fato de não precisar pintar os cabelos? 0 fato de poder não seguir regras em relação à aparência física? Ou o fato de que o envelhecimento deve ser aceito pela sociedade? São sentidos possiveis enunciados pelos textos.

E, finalmente em 2018, no dia 28 de janeiro, a autora publica a matéria "Cada vez mais mulheres fazem opção por não pintar o cabelo"13. Essa matéria enumera uma série de mulheres que deixaram de pintar seus cabelos, assumindo os brancos. Entretanto, algumas delas sofreram por conta de críticas de pessoas que dizem ser "relaxamento" o ato de assumir os cabelos brancos.

I39 Além das matérias publicadas no site mencionado, pode-se encontrar vários grupos de Facebook centrados na temática cabelos brancos/ grisalhos. Alguns exemplos são: "Tenho cabelos brancos, e dai?"; "Revolução grisalha"; "Cabelos brancos e grisalhos"; "Branco e prata"; "Cabelos brancos e lindos"; "Cabelo branco"; "Grisalhos brilhantes"; "Meus cabelos brancos", "Projeto grisalha"; "Projeto cabelos grisalhos/brancos".

Nesses espaços midiáticos, os participantes, mulheres na maioria, discutem os significados do cabelo branco postando fotos suas com os cabelos brancos ou grisalhos. Ou seja, torna-se um espaço de relato e de interação, no qual as mulheres reafirmam suas escolhas, o não pintar mais os cabelos e assumir os brancos, e também se motivam, estabelecendo uma relação de parceria e compreensão. Esses grupos aparentemente dão força àquelas mulheres que optam por aceitar que seus cabelos perdem a cor com o passar dos anos.

Nesses grupos, muitas mulheres apresentam e discutem a transição dos cabelos coloridos para grisalhos e brancos, enfatizando que, ao deixarem esse processo ocorrer, de forma natural ou com auxílio de um profissional, a sensação é de liberdade, associando o fato de usarem tintura nos cabelos como escravidão, prisão. Verifica-se que a sociedade exerce certa força ao sugerir/exigir que a mulher esconda os efeitos do tempo nos cabelos, disfarçando essa passagem com a pintura. 
A temática dos cabelos brancos/grisalhos também é tratada em sites de jornais e revistas, como matéria publicada em 14 de julho de 2017 pela

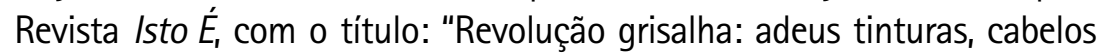
brancos estão na moda"14. Essa matéria foi reproduzida no site 50 e mais, conforme já mencionado.

0 site Modices também tratou do assunto, em 7 de agosto de 2017, com o texto: "Em paz com o cabelo branco: como assumir o visual grisalho e levar a autoestima lá pra cima"15. Na matéria são apresentadas várias mulheres famosas e anônimas que resolveram assumir os cabelos brancos de vez. São apresentadas sugestões de cortes e de penteados para esses cabelos. Interessante verificar que o título da matéria sugere que os cabelos brancos podem diminuir a autoestima de alguém - seria a confirmação do envelhecimento? A perda de juventude? -, reiterando a cobrança da "boa aparência" realizada pela sociedade.

0 site da revista Marie Claire publicou, em 11 de março de 2017, a matéria "Tudo o que você precisa saber sobre cabelos brancos"16, discutindo como e porquê aparecem os fios brancos, bem como devem ser tratados. Além disso, apresentou alguns exemplos de famosos que passaram a usar os cabelos brancos.

Assim, o que se percebe é que o fato de deixar os cabelos de maneira natural, indicando que o envelhecimento está se processando no indivíduo, é de algo revolucionário, pois contraria a orientação social de tingir os cabelos brancos.

Com os textos mencionados, pode-se observar que a temática cabelos brancos/grisalhos tornou-se algo recorrente nos espaços midiáticos, fazendo circular novos sentidos sobre esse signo.

Outro aspecto, de acordo com os sites e páginas de Facebook observadas, foi a aceitação do aparecimento e uso dos brancos com mais tranquilidade, ao menos para as mulheres que os adotam, pois encontram, como pode ser visto em sites e grupos de Facebook, apoio para tal alteração fisica. Entretanto, é preciso observar que em algumas publicações são utilizadas imagens de mulheres famosas, atrizes, apresentadoras, modelos como símbolos da possibilidade de aceitação dessa nova condição: a perda de cor dos cabelos. Essa estratégia discursiva parece acalentar as demais mulheres, pois, em um país como este, que prioriza a aparência, se aquelas mulheres consideradas modelos de corporeidades assumem seus brancos, todas as demais também podem fazê-lo.

\section{Algumas conclusões}

0 corpo humano tem se mostrado como texto e linguagem nos processos de midiatização. Texto, pois enuncia mensagens a partir 
do arranjo de inúmeros signos utilizados pelos indivíduos, como sus roupas, seus acessórios, sua postura, cor e formas de arrumar os cabelos, entre outros aspectos. Também é linguagem, pois estabelece a mediação entre o próprio indivíduo e a sociedade, evidenciando em si mesmo seu posicionamento em relação a uma série de situações.

Neste artigo, a proposta foi refletir/inferir acerca dos possiveis significados que os cabelos brancos/grisalhos podem ter para mulheres que assumem seu uso. Optou-se por verificar como esses sentidos circulam em espaços midiáticos virtuais, como sites e páginas de Facebook.

Percebe-se que há claro estímulo por parte de alguns veículos de comunicação na valorização dos brancos, muitas vezes contrariando o senso comum, ou seja, de que os brancos podem refletir desleixo, aumentar visualmente a idade da pessoa, por exemplo.

A postura assumida nesses espaços pode colaborar para que certas normas ou padrões estéticos e visuais arraigados na sociedade brasileira sejam questionados e rompidos, estimulando a aceitação de certos fatos, como o envelhecimento, por exemplo, dando a esse processo a naturalidade que ele deve ter.

Evidentemente, não se deve esquecer que mesmo que as mulheres assumam seus cabelos brancos, ou seja, o processo de envelhecimento, o mercado estará disponivel para oferecer todos os produtos necessários para a manutenção deles.

Apesar disso, é importante que a sociedade perceba o envelhecer como um processo natural e inevitável, e que a presença de idosos se tornará cada vez mais recorrente em todos os espaços sociais.

Recebido: 2-10-2018

Aprovado: 5-11-2018 


\section{NOTAS}

${ }^{1}$ PORFÍRIO, Anita. Mulheres de 30, 40 e 50 anos recusam a tintura e assumem os cabelos brancos. IG, 8 ago. 2013. Delas. Disponivel em: https://delas.ig.com.br/beleza/cabelos/2013-08-08/mulheres-de-30-40-e-50anos-recusam-a-tintura-e-assumem-os-cabelos-brancos.html. Acesso em: 1 out. 2018.

2 SANTANA, Maya. Ainda jovem, elas estão assumindo cabelos brancos. 50emais. Disponivel em: http:// www.50emais.com.br/ainda-jovem-elas-estao-assumindo-os-cabelos-brancos/. Acesso em: 1 out. 2018.

${ }^{3}$ SANTANA, Maya. Elas assumem cada vez mais jovens os fios brancos. 50emais, 18 ago. 2013. Disponivel em: http://www.50emais.com.br/elas-assumem-cada-vez-mais-jovens-os-fios-brancos/. Acesso em: 1 out. 2018. e SANTANA, Maya. A musa dos cabelos brancos. 50emais, 24 set. 2013. Disponivel em: http:// www.50emais.com.br/a-musa-de-cabelos-brancos/. Acesso em: 1 out. 2018.

${ }^{4}$ SANTANA, Maya. Mulheres que deixam o tempo agir naturalmente. 50emais. 10 set. 2014. Disponivel em: http://www.50emais.com.br/mulheres-que-deixam-o-tempo-agir-naturalmente/. Acesso em: 2 out. 2018.

5 SANTANA, Maya. Mulheres revelam porque assumiram os cabelos brancos. 50emais. 28 set. 2015. Disponivel em: http://www.50emais.com.br/page/3/?s=cabelos+brancos. Acesso em 1 out. 2018

${ }^{6}$ SANTANA, Maya. Precisamos fazer a rebelião dos cabelos brancos. 50emais. 25 abr. 2015. Disponivel em: http://www.50emais.com.br/page/3/?s=cabelos+brancos. Acesso em: 1 out. 2018.

7 SANTANA, Maya. Uma breve história de como parei de pintar meus cabelos. 50emais. 11 dez. 2015. Disponivel em: http://www.50emais.com.br/page/3/?s=cabelos+brancos. Acesso em: 1 out 2018.

${ }^{8}$ SANTANA, Maya. Cabelos grisalhos: como adotá-los com charme e leveza. 50emais. 14 jul.2016. Disponível em: http://www.50emais.com.br/page/3/?s=cabelos+brancos. Acesso em: 1 out 2018.

${ }^{9}$ SANTANA, Maya. Boas histórias de libertação e de aceitação dos cabelos brancos. 50emais.19 jul. 2017. Disponivel em: http://www.50emais.com.br/page/3/?s=cabelos+brancos. Acesso em: 1 out. 2018.

10 SANTANA, Maya. Revolucão na cabeça das mulheres: a moda dos cabelos brancos. 50emais. 17 ago. 2017. Disponivel em: http://www.50emais.com.br/page/3/?s=cabelos+brancos. Acesso em: 1 out. 2018.

${ }^{11}$ SANTANA, Maya. Com tantas adeptas, onda dos cabelos brancos chegou para ficar. 50emais. 23 out. 2017. Disponivel em: http://www.50emais.com.br/page/3/?s=cabelos+brancos. Acesso em: 1 out. 2018.

${ }^{12}$ SANTANA, Maya. Assumir a cabeleira branca significa aceitação e libertação. 50emais. 28 nov. 2017. Disponivel em: http://www.50emais.com.br/page/3/?s=cabelos+brancos. Acesso em: 1 out. 2018.

${ }^{13}$ SANTANA, Maya. Cada vez mais mulheres fazem opção por não pintar o cabelo. 50emais. 28 jan. 2018. Disponivel em: http://www.50emais.com.br/page/3/?s=cabelos+brancos. Acesso em: 1 out. 2018.

${ }^{14}$ Revolução grisalha: adeus tinturas, cabelos brancos estão na moda. Isto É. 14 ago. 2017. Disponivel em: https://istoe.com.br/revolucao-grisalha-adeus-tinturas-cabelos-brancos-estao-na-moda/. Acesso em: 3 out. 2018.

${ }^{15} \mathrm{Em}$ paz com o cabelo branco: como assumir o visual grisalho e levar a autoestima lá pra cima. Modices, 7 ago. 2017. Disponivel em: https://www.modices.com.br/beleza/cabelo-branco-como-usar-grisalho/. Acesso em: 3 out. 2018.

${ }^{16}$ TUDO o que você precisa saber sobre cabelos brancos. Revista Marie Claire. 10 mar. 2017. Disponivel em: https://revistamarieclaire.globo.com/Beleza/noticia/2017/03/tudo-o-que-voce-precisa-saber-sobrecabelos-brancos-esta-aqui.html. Acesso em: 3 out. 2018 


\section{REFERÊNCIAS}

BEAUVOIR, Simone de. A velhice: as relações com o mundo. Tradução de Heloysa de Lima Dantas. São Paulo: Editora Difusão Européia do Livro, 1970.

BRASIL Presidência da República. Secretaria de Direitos Humanos. Secretaria Nacional de Promoção e Defesa dos Direitos Humanos. Dados sobre o envelhecimento no Brasil. Brasilia, DF: Coordenação Geral dos Direitos do Idoso, 2013. Disponivel em http://www.educadores.diaadia.pr.gov.br/arquivos/ File/pdf/envelhecimento.pdf. Acesso em: 5 set. 2018.

DEBERT, Guita G. A reinvenção da velhice: socialização e processos de reprivatização do envelhecimento. São Paulo: Editora da Universidade de São Paulo, FAPESP, 2012.

DEBERT, Guita G. A dissolução da vida adulta e a juventude como valor. Horizontes Antropológicos, Porto Alegre, ano 16, n. 34, p. 49-70, jul./dez. 2010. Disponivel em: http://dx.doi.org/10.1590/S010471832010000200003. Acesso em: 20 jul. 2018.

DINO. Idosos apostam na tecnologia para se relacionar e abandonar a solidão. Exame, 23 nov. 2017 Disponivel em: https://exame.abril.com.br/negocios/dino/idosos-apostam-na-tecnologia-para-serelacionar-e-abandonar-a-solidao/. Acesso em: 1 out. 2018.

GARCIA, Wilton. Corpo, mídia e representação: estudos contemporâneos. São Paulo: Pioneira Thomson Learning, 2005.

GARDIN, Carlos. 0 corpo mídia: modos e moda. In: OLIVEIRA, Ana C. de; CASTILHO, Kathia (org.). Corpo e Moda: por uma compreensão do contemporâneo. Barueri: Estação das Letras e Cores Editora, 2008.

GOLDENBERG, Mirian. 0 corpo como capital: para compreender a cultura brasileira. Arquivos em Movimento, Rio de Janeiro, v. 2, n. 2, julho/dezembro, 2006.

GOMES, Pedro G. Dos meios às mediações: um conceito em evolução. São Leopoldo: Editora Unisinos, 2017.

IBGE. Perfil dos idosos responsáveis pelos domicílios. Comunicação Social. 25 de julho de 2002. Disponivel em: https://ww2.ibge.gov.br/home/presidencia/noticias/25072002pidoso.shtm. Acesso em: 3 out. 2018.

LISA. Grey Revolution. Adventure Lisa. 13 ago. 2014. Disponivel em: http://adventurelisa.blogspot. com/2014/08/grey-revolution.html. Acesso em: 1 out. 2018.

VILLAÇA, Nizia. A edição do copo: tecnociência, artes e moda. Barueri: Estação das Letras e Cores, 2007.

WORLD HEALTH ORGANIZATION. Envelhecimento ativo: uma política de saúde. Tradução Suzana Gontijo. Brasilia: Organização Pan-Americana da Saúde, 2005. Disponivel em: http://bvsms.saude. gov.br/bvs/publicacoes/envelhecimento_ativo.pdf. Acesso em: 20 jul. 2018. 